\title{
Desain dan Manufaktur Model Piston Jupiter MX 135 cc Dengan Menggunakan 3D Printer
}

\author{
Wandro J. Siregar ${ }^{1}$, Richard A. M.Napitupulu ${ }^{2, *}$, Parulian Siagian ${ }^{2}$ \\ ${ }^{1}$ Mahasiswa Prodi Teknik Mesin Universitas HKBP Nommensen, Medan-Indonesia \\ ${ }^{2}$ Dosen Prodi Teknik Mesin Universitas HKBP Nommensen, Medan-Indonesia \\ * richard_alf@yahoo.com
}

\begin{abstract}
A product that will be mass produced requires an initial prototype so that it can assess whether a product design meets the desired criteria and is ready to be mass produced. For the purposes of making the initial prototyping, one alternative is to use 3D printing. Prototyping is an early example of a concept as part of the product development process. Rapid Prototyping allows the visualization of a 3D (threedimension) image into an original three-dimensional object that has a volume. In addition, rapid prototyping products can also be used to test certain parts. In the design process the 2017 Solidworks software and manufacturing process are used anet type 3D printer. In the manufacturing process many 3D Printer parameters must be regulated and very influential on the manufacturing results to be obtained, including the 3D printer parameter settings in the slicing process. This is a process that is very influential on the results, where the process of slicing the material temperature, printing speed, wall thickness, layer thickness and support must be set properly. In the future it is expected that research on 3D printing manufacturing results with the same printer parameters for the design results of some CAD software.
\end{abstract}

Keywords : design prototyping, Rapid Prototyping, 3D Printer, Software Slicing

\section{PENDAHULUAN}

Dewasa ini, perubahan jaman semakin cepat dengan perkembangan yang begitu pesat. Akibatnya, percepatan aktivitas manusia merupakan keniscayaan yang tidak bisa ditolak.Hal inilah yang memicu munculnya teknologi-teknologi terbaru. Filosofinya tentu untuk membantu menyelesaikan tugas-tugas manusia dengan biaya dan tenaga seminimal mungkin. Salah satu teknologinya adalah teknologi 3D Printing [1]. Saat ini, teknologi pencetakan 3D memainkan peran penting dalam pengembangan produk, pembuatan prototype, dan manufaktur.

Dalam industri manufaktur, desain suatu produk menjadi bagian yang sangat penting mengingat begitu ketatnya persaingan dan cepatnya inovasi-inovasi yang dikeluarkan oleh produsen untuk mendapatkan pasar penjualan. Beberapa perusahaan manufaktur melakukan pengembangan produk, yaitu proses dimana konsep produk harus diterjemahkan dari gambar teknik menjadi produk phisik. Pembuatan produk phisik model pertama atau prototype dinamakan prototyping. Prototyping sangat penting karena merupakan makna terakhir dalam verifikasi bentuk, kesesuaian, dan fungsi produk.

Sebuah produk yang akan diproduksi secara massal memerlukan sebuah prototype awal sehingga bisa menilai apakah suatu produk desain telah memenuhi kriteria yang diinginkan dan siap untuk diproduksi secara massal. Prototyping akan sangat membantu menentukan proses produksi selanjutnya dan nilai investasi yang harus dikeluarkan. 
Untuk keperluan pembuatan prototyping awal tersebut, salah satu alternatifnya adalah menggunakan 3D printing.

\subsection{Desain}

Desain adalah proses menterjemahkan ide-ide baru atau kebutuhan pasar menjadi informasi detil suatu produk dapat dibuat. Setiap langkah-langkah desain membutuhkan keputusan untuk menggunakan material apa dalam membuat produk tersebut dan proses pembuatannya. Umumnya pemilihan material itu ada didalam standard desain.Tetapi kadang-kadang suatu produk baru atau kelanjutan dari produk sebelumnya dapat dibuat atau disarankan untuk dibuat dengan material baru [2].

\subsection{Prototyping}

Prototyping adalah contoh awal konsep sebagai bagian dari proses pengembangan produk. Prototype melayani berbagai tujuan, baik dari sudut pandang bisnis maupun teknik.Bisnis menggunakan prototype untuk mengumpulkan umpan balik pelanggan yang terperinci tentang masalah-masalah seperti estetika, ergonomik, dan tema.Serta untuk riset pemasaran dan analisis biaya. Prototyping digunakan oleh para insinyur untuk menyediakan data manufaktur dan perakitan (assembly), untuk menyelidiki integrasi sistem masalah dan untuk mengembangkan analisis dan strategi pengujian. Dalam beberapa kasus, prototyping juga digunakan di fase generasi konsep dari proses desain untuk membantu desainer untuk memperluas atau mengontrak himpunan konsep yang mungkin. Jelas prototyping adalah bagian penting dari sebagian besar proses desain.

\subsection{Rapid Prototyping}

Rapid Prototyping (RP) dapat didefenisikan sebagai metode-metode yang digunakan untuk membuat model berskala (prototype) dari mulai bagian suatu produk (part) ataupun rakitan produk (assembly) secara cepat dengan menggunakan data Computer-Aided Design (CAD) tiga dimensi. Rapid Prototyping memungkinkan visualisasi suatu gambar 3D (tiga dimensi) menjadi benda tiga dimensi asli yang mempunyai volume.Selain itu produk-produk rapid ptototyping juga dapat digunakan untuk menguji part tertentu.

Paket perangkat lunak mengiris model CAD menjadi jumlah lapisan tipis $=0,1$ mm tebal yang mungkin dibangun satu diatas yang lain. Proses manufaktur ini adalah "Proses Aditif'sedangkan proses manufaktur dengan proses pemesinan adalah "Proses Subtraktif”.

Ada 5 teknik (metode) rapid prototyping, yaitu:

a. Stereo Lithography (SLA)

SLA adalah proses pembuatan aditif dalam bentuknya yang paling umum. Dimana bekerja dengan memfokuskan laser ultraviolet (UV) pada tong resin photopolymer. Dengan bantuan Computer-Aided Manufacturing atau Computer-Aided Design.

b. Laminated Object Manufacture (LOM)

Laminated object manufacturing (LOM) adalah sistem rapid prototyping yang dikembangkan oleh Helisys Inc (Cubic Technologies sekarang merupakan organisasi penerus Helisys). Di dalamnya, lapisan kertas berlapis perekat, plastik, atau laminasi logam secara berturut-turut direkatkan bersama dan dipotong menjadi bentuk dengan pisau atau pemotong laser. 


\section{c. Selective Laser Sintering (SLS)}

Selective laser sintering (SLS) adalah teknik pembuatan aditif manufaktur (AM) yang menggunakan laser sebagai sumber daya untuk menyinter bahan bubuk (biasanya nilon atau poliamida), mengarahkan laser secara otomatis pada titik-titik di ruang yang ditentukan oleh model 3D, mengikat bahan bersama-sama untuk menciptakan struktur yang solid [3].

\section{d. Fused Deposition Modeling (FDM)}

Fused filament fabrikasi (FFF), juga dikenal dengan istilah Fused Deposition Modeling (FDM), yang kadang-kadang juga disebut fabrikasi bentuk bebas filamen, adalah proses pencetakan 3D yang menggunakan filamen terus-menerus dari bahan termoplastik. Filament diumpankan dari koil besar melalui kepala, mesin pengekstrusi printer yang dipanaskan, dan disimpan pada pekerjaan yang sedang berkembang.Print head dipindahkan di bawah kendali komputer untuk menentukan bentuk cetakan. Biasanya kepala bergerak dalam dua dimensi untuk menyimpan satu bidang horizontal, atau lapisan, pada satu waktu; pekerjaan atau print head kemudian dipindahkan secara vertikal dengan jumlah kecil untuk memulai layer baru. Kecepatan kepala ekstruder juga dapat dikontrol untuk berhenti dan memulai pengendapan dan membentuk bidang yang terputus tanpa merangkai atau menggiring bola antar bagian. "Pembuatan filamen menyatu" diciptakan oleh anggota proyek RepRap untuk memberikan frasa yang secara hukum tidak akan dibatasi dalam penggunaannya, diberikan merek dagang yang mencakup "pemodelan deposisi peleburan".

e. 3D Printer

Proses 3D printer membangun objek tiga dimensi dari model computer-aided design (CAD), biasanya dengan menambahkan bahan lapis demi lapis secara berturutturut, itulah sebabnya ia juga disebut aditif manufakturing, tidak seperti permesinan konvensional, pengecoran dan penempaan proses, dimana bahan dihilangkan dari persediaan barang (subtraktif manufaktur) atau dituangkan ke dalam cetakan dan dibentuk dengan cara mati, tekan dan palu. Istilah "pencetakan 3D" mencakup berbagai proses di mana bahan bergabung atau dipadatkan di bawah kendali komputer untuk membuat objek tiga dimensi, dengan bahan yang ditambahkan bersama-sama (seperti molekul cair atau butiran serbuk disatukan bersama-sama), biasanya lapis demi lapisan. Pada 1990-an, teknik pencetakan 3D dianggap hanya cocok untuk produksi prototipe fungsional atau estetika dan istilah yang lebih tepat untuk itu adalah rapid prototyping. Pada 2019 presisi, pengulangan dan jangkauan material telah meningkat ke titik bahwa beberapa proses pencetakan 3D dianggap layak sebagai teknologi produksi industri, di mana istilah aditif manufakturing dapat digunakan secara sinonim dengan "pencetakan 3D" [3-4]. Salah satu keuntungan utama dari pencetakan 3D adalah kemampuan untuk menghasilkan bentuk atau geometri yang sangat kompleks, dan prasyarat untuk memproduksi bagian cetak 3D adalah model 3D digital atau file CAD.

\section{BAHAN DAN METODE}

\subsection{Bahan}

- Bahan yang digunakan diantaranya yaitu :
$>$ Piston
$>$ Pen piston
$>$ Batang piston
$>$ Filament PLA 
- Peralatan yang digunakan diantaranya yaitu :
$>$ Mesin 3D Printer
$>$ Laptop/PC
$>$ Jangka sorong
$>$ Mistar
$>$ Water pass

\subsection{Metode}

Tahapan proses Prototyping, yaitu :

1. Membuat model CAD dari objek yang dirancang (didesain) dengan menggunakan solidworks 2017

2. Mengubah model CAD menjadi format file STL

3. Pengaturan parameter Printer dan mengiris STL file kedalam beberapa potongan (layers) dengan menggunakan software slicer Ultimaker Cura

4. Membangun model secara lapis perlapis (proses manufaktur) dengan menggunakan 3D printer

5. Membersihkan dan penyempurnaan model objek hasil manufaktur (finishing)

\section{HASIL DAN PEMBAHASAN}

Pada 3D printer, proses slicing memegang peran penting untuk memperoleh hasil yang maksimal. Dimana diperlukan setting parameter yang akurat, seperti pengaturan ketebalan dinding, pengisi, temperatur PLA, temperaturbuild plate, kecepatan printer, support, dan lain-lain. Selain parameter-parameter tersebut posisi penempatan objek juga sangat berpengaruh dalam proses pencetakan karena, apabila objek yang akan dicetak memiliki banyak sudut-sudut atau bagian yang menggantung maka dalam hal ini sangat diperlukan pengaturan support dalam tahap slicing.Dalam hal ini penulis mengambil posisi tegak, dengan posisi seperti ini akan menghasilkan permukaan atas 3D objek yang lebih halus/bagus dibandingkan dengan posisi 3D objek bagian atas berada dibawah atau menempel pada build plate. Posisi ini memerlukan banyak support namun hanya mulai bagian tengah sampai dasar yang memerlukan support, sehingga bentuk permukaan atas objek tidak akan dipengaruhi oleh support.

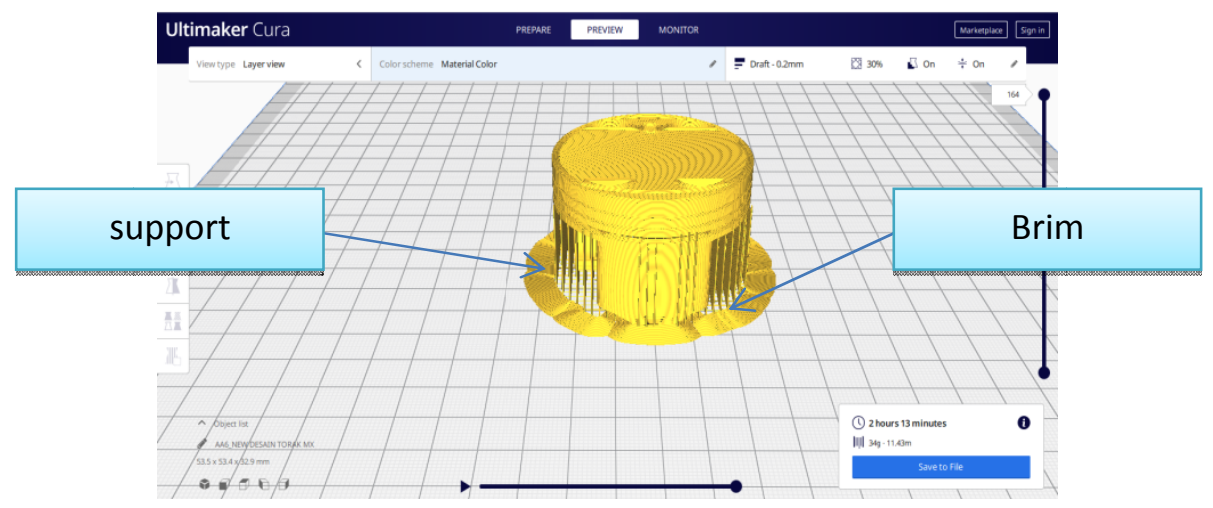

Gambar 1. Pengaturan parameter printer pada proses slicing piston

Disini penulis menggunakan parameter printer seperti dibawah ini :

- Proses slicing menggunakan : Ultimaker Cura

- Diameter Nozzel : $0.4 \mathrm{~mm}$ 
- Jenis filament : PLA

- Infil (pengisi) : 30\%

- Infil patrern : line (garis)

- Infil support : 15\%

- Support pattern : Line (garis)

- Support Z distance : $0.3 \mathrm{~mm}$

- Waktu Print pada software cura : 2 jam 13 menit

- Waktu print pada mesin 3D printer : 2 jam 57 menit

- Berat /panjang PLA yang dibutuhkan dalam proses manufaktur : 34 gram/ $11.43 \mathrm{~m}$

- Print speed : $80 \mathrm{~mm} / \mathrm{s}$

- $\quad$ Fan speed (kecepatan kipas) : 60\%

- Printing temperature $: 180^{\circ} \mathrm{C}$

- Build plate temperature : $50^{\circ} \mathrm{C}$

- $\quad$ Layer height : 0.2

- $\quad$ Wall thickness : $1.6 \mathrm{~mm}$

Pada tahap pengaturan parameter printer pada software slicing untuk proses manufaktur piston ini kecepatan printer yaitu $80 \mathrm{~mm} / \mathrm{s}$ dengan temperatur printing $180^{\circ} \mathrm{C}$. Ini merupakan variable yang paling sesuai dalam proses manufaktur piston ini. Variable yang harus diperhatikan selain kecepatan printer dan juga temperature printer yaitu variable support dan quality (lapisan). Dalam proses pengaturan parameter printer ini penulis telah memperoleh variable support dan quality yang sesuai untuk mendukung menghasilkan manufaktur yang bagus. Parameter-parameter diatas merupakan parameter yang terbaik untuk manufaktur piston ini. Dimana penulis telah melakukan uji coba sebanyak 4 kali dengan pengaturan parameter yang bervariasi dan parameter diatas merupakan hasil analisa dari 4 percobaan yang telah dilakukan sebelumnya.
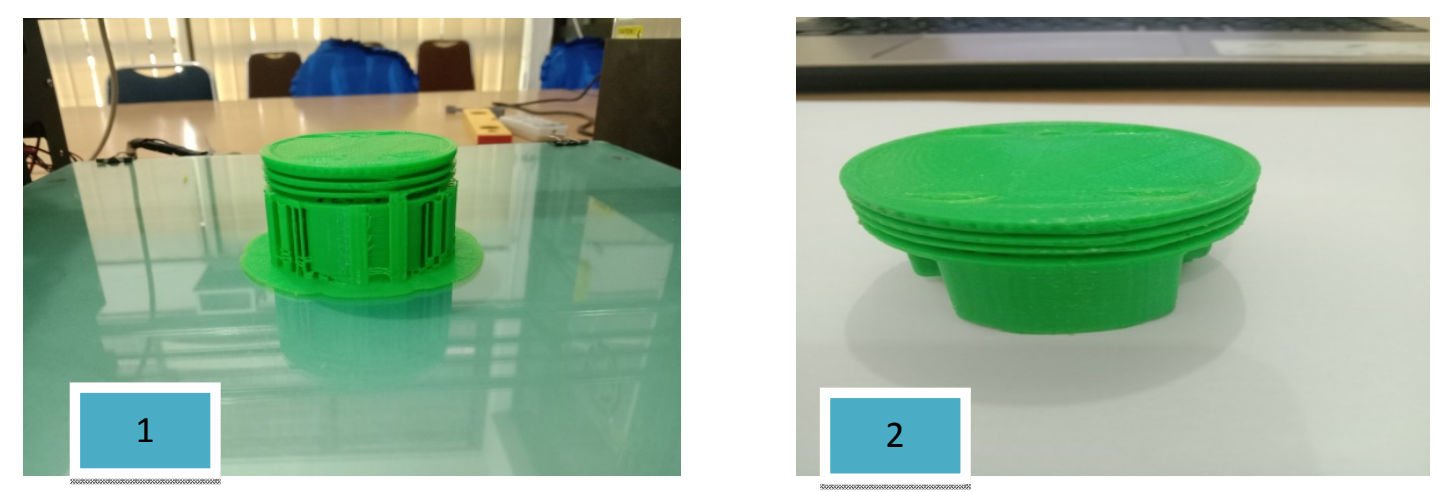

Gambar 2. Hasil manufaktur 3D printer

Keterangan gambar :

1. Hasil manufaktur sebelum difinishing/ dibersihkan dari support

2. Hasil manudaktur setelah dibersihkan dari support 


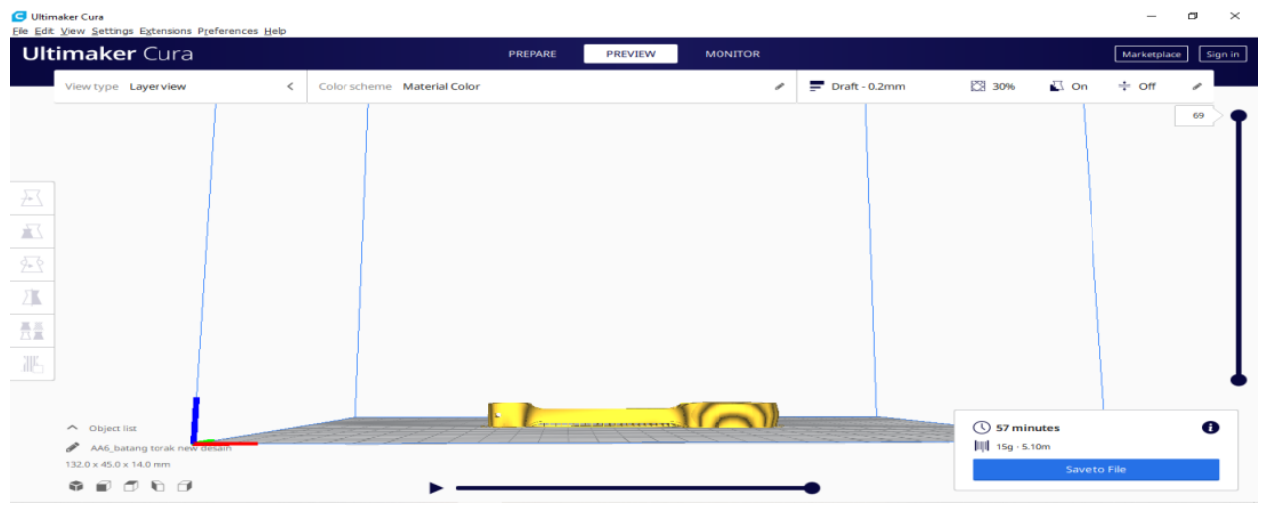

Gambar 3. Pengaturan parameter printer pada proses slicing batang piston

Parameter 3D printer yang digunakan pada proses slicing diantaranya adalah sebagai berikut :

- Proses slicing menggunakan : Ultimaker Cura

- Diameter Nozzel : $0.4 \mathrm{~mm}$

- Jenis filament : PLA

- Infil (pengisi) : 30\%

- Infilpatrern : line (garis)

- Infil support : $15 \%$

- $\quad$ Support Z distance : $0.2 \mathrm{~mm}$

- Waktu Print pada software cura : 57 menit

- Waktu print pada mesin 3D printer : 1 jam 2 menit

- Berat /panjang PLA yang dibutuhkan dalam proses manufaktur : 15 gram/ $5.10 \mathrm{~m}$

- Print speed : $80 \mathrm{~mm} / \mathrm{s}$

- Fan speed (kecepatan kipas) : 60\%

- Printing temperature $: 180^{\circ} \mathrm{C}$

- Build plate temperature $: 50^{\circ} \mathrm{C}$

- Build plate Adhesion type : Brim

- $\quad$ Layer height : $0.2 \mathrm{~mm}$

- Wall thickness : $1.6 \mathrm{~mm}$

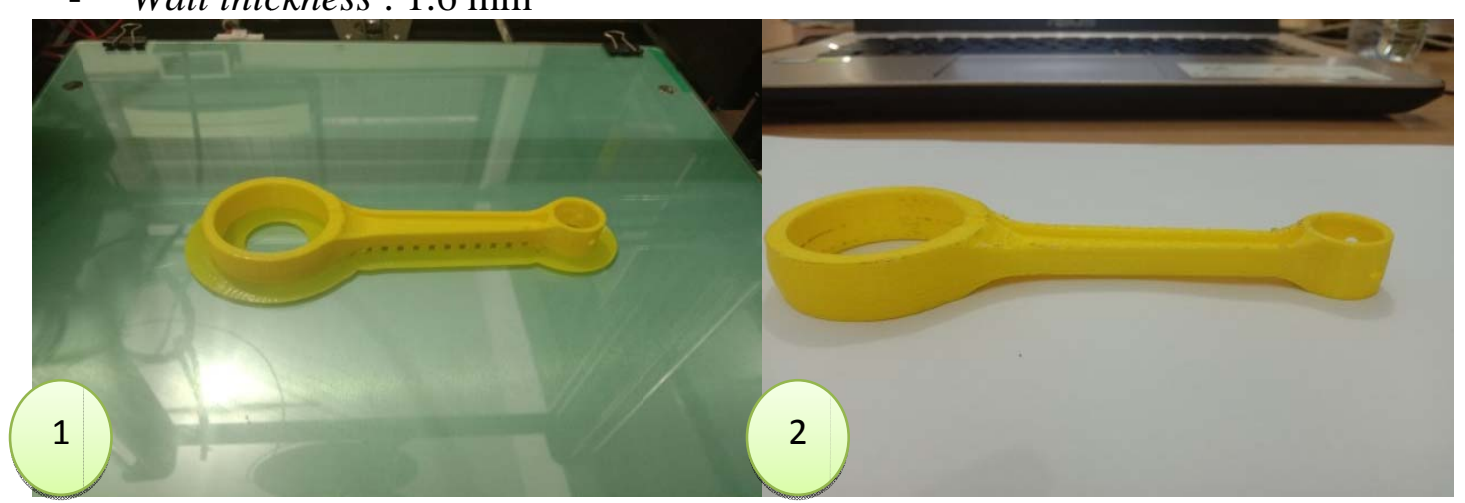

Gambar 4. Hasil manufaktur 3D Printer

Keterangan gambar :

1. Hasil manufaktur 3D printer sebelum dibersihkan dari support 
2. Hasil manufaktur setelah dibersihkan dari support

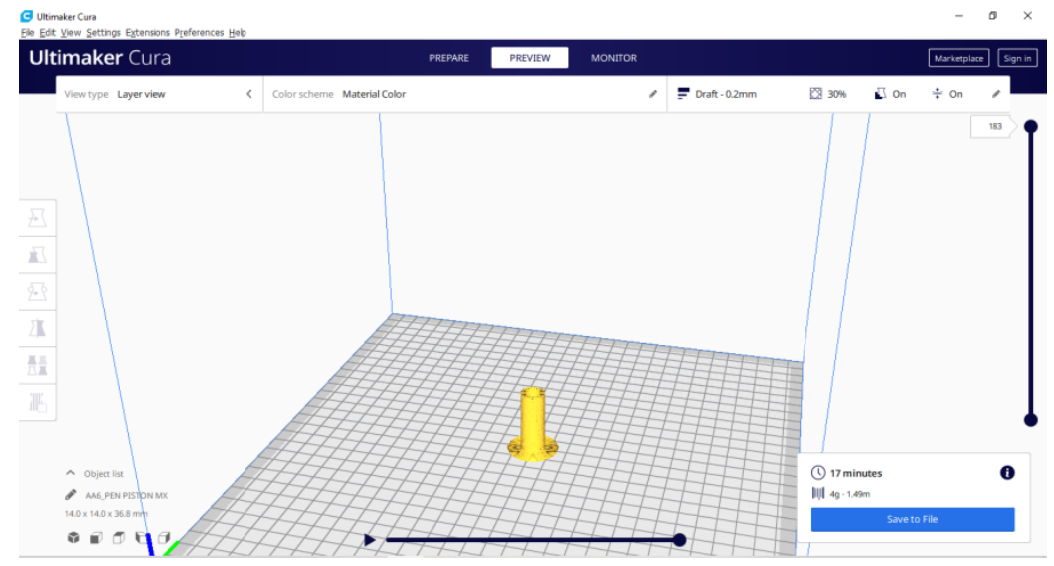

Gambar 5. Pengaturan parameter printer pada proses slicing pen piston

Parameter 3D printer yang digunakan pada proses slicing diantaranya adalah sebagai berikut :

- Proses slicing menggunakan : Ultimaker Cura

- Diameter Nozzel : $0.4 \mathrm{~mm}$

- Jenis filament : PLA

- Infil (pengisi) : 40\%

- Waktu Print pada software cura : 17 menit

- Waktu print pada mesin 3D printer : 20 menit 54 detik

- Berat /panjang PLA yang dibutuhkan dalam proses manufaktur : 4 gram/ $1.49 \mathrm{~m}$

- Print speed : $80 \mathrm{~mm} / \mathrm{s}$

- Fan speed (kecepatan kipas) : 60\%

- Printing temperature $: 180^{\circ} \mathrm{C}$

- Build plate temperature $: 50^{\circ} \mathrm{C}$

- Layer height : $0.2 \mathrm{~mm}$

- Wall thickness : $1.2 \mathrm{~mm}$

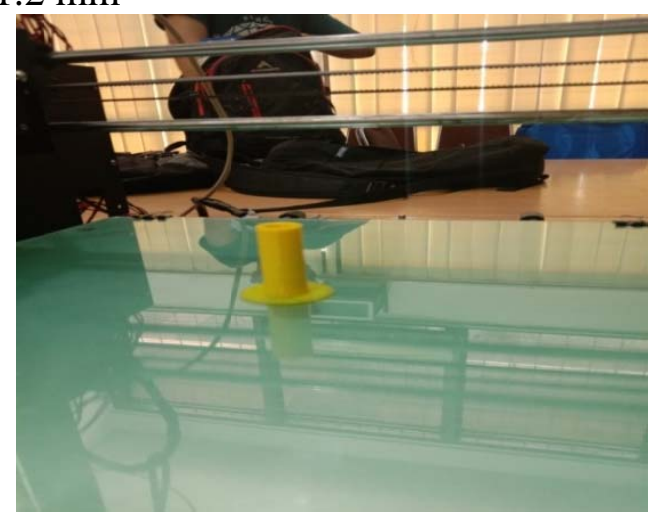

Gambar 6. Hasil manufaktur 3D Printer 


\section{KESIMPULAN}

Dari hasil perancangan dan manufaktur didapat kesimpulan sebagai berikut :

1. Perancangan kepala piston, connecting rod (batang piston), dan pen piston dengan menggunakan software SOLIDWORKS 2017.

2. Hasil manufaktur menggunakan $3 \mathrm{D}$ printer sangat bagus, dimana hasil desain dapat diterjemahkan ke 3D printer dan menghasilkan benda yang sesuai dengan hasil desain dari software solidworks. Keberhasilan dalam proses manufaktur ini diperoleh dari hasil pengaturan parameter-parameter 3D printer pada saat proses slicing yang tepat, seperti pengaturan temperature material, support, kecepatan printer, kecepatan kipas, quality (tebal lapisan), shell (tebal dinding), infill (pengisi), dan lain sebagainya.

3. Temperatur dan kecepatan printing yang paling sesuai untuk proses manufaktur piston, dan batang piston ini adalah $180^{\circ} \mathrm{C}$ dan $80 \mathrm{~mm} / \mathrm{s}$ dengan support Z distance sebesar $0.3 \mathrm{~mm}$, infil support 15\% dan ketebalan lapisan (layer height) sebesar $0.2 \mathrm{~mm}$.

4. Bahan atau material yang digunakan dalam proses manufaktur adalah PLA (Poly Lactic Acid). PLA merupakan bahan yang paling sering digunakan dalam penggunaan 3D printer karena harga PLA yang relativ murah dan ramah lingkungan.

5. Proses manufaktur tidak memakan banyak waktu, dimana proses manufaktur paling lama yaitu hanya 2 jam 57 menit atau hampir 3 jam untuk proses manufaktur kepala piston, untuk connecting rod (batang piston) yaitu 1 jam 2 menit dan untuk pen piston yaitu 20 menit 54 detik.

\section{DAFTAR PUSTAKA}

1. D.V. Mahindru, Priyanka Mahendru.(2013). Review of Rapid PrototypingTechnology for the Future. Global Jurnal. Inc (USA), 13.

2. Hamzah, Hairul Hisham, Saiful, Arifin Shafiee, Aya, Abdalla, Patel, Bhavik Anil (2018). 3D printable conductive materials for the fabrication of electrochemical sensors: A mini review. Electrochemistry Communications. 96.

3. Bose, Animesh, Schuh, Christopher A, Tobia, Jay C, Tuncer, Nihan, Mykulowycz, Nicholas M., Preston, Aaron, Barbati, Alexander C, Kernan, Brian, Gibson, Michael A. (2018-06-01). "Traditional and additive manufacturing of a new Tungsten heavy alloy alternative". International Journal of Refractory Metals and Hard Materials. 73.

4. Sun, Jie; Zhou, Weibiao, Huang, Dejian, Fuh, Jerry Y. H, Hong, Geok Soon (2015-08-01). "An Overview of 3D Printing Technologies for Food Fabrication". Food and Bioprocess Technology. 8. 